\title{
Familia y televisión: algunas representaciones de la familia española en la pequeña pantalla
}

\section{Family and Television: Some Pictures of Spanish Family on the Small Screen}

Ma del Mar Chicharro Merayo, profesora de Teoría y Sociología de la Comunicación. CES Felipe II (UCM)

Recibido: 3-XII-2008 - Aceptado: 26-II-2009

Resumen:

El presente trabajo pretende explorar la capacidad de la televisión para reflejar algunas de las dinámicas de cambio social que afectan a la sociedad española, especialmente las relacionadas con la institución familiar. Para ello, en primer lugar, nos sitúa en el contexto de una sociedad en cambio, así como de una televisión en transformación. Seguidamente, analiza las características, así como los significados asociados a algunos relatos televisivos de actualidad, narrados en clave familiar. A partir de ahí, explora las funciones más relevantes que realiza la pequeña pantalla para sus espectadores, así como las diferentes lecturas que el medio televisivo hace del entorno familiar.

Palabras clave:

Televisión, familia, cambio social.

Abstract:

This paper tries to explore the ability of television to show some of the social change trends connecting with Spanish society, specially those related to familiar institution. In this way, first of all it places us in the context of a society in change, as well as a television in transformation. Following, it analyses the features and also de meanings of some television stories in present, told in a familiar tone. After that, it explores the main functions that television provides its audience, as well as the different pictures of family that this media draws.

Key words:

Television, family, social change. 


\section{Introducción: televisión y cambio social ${ }^{1}$}

La estructura de las sociedades occidentales del siglo XXI se configura conforme a algunos elementos que marcan diferencias en relación con formas sociales anteriores. Obviamente, el caso español, como el resto de los entornos sociales circundantes, no ha podido escapar a la influencia troqueladora del conocimiento y la información. Tanto es así que el valor que adoptan en el contexto actual este tipo de variables se manifiesta a su vez en forma de dinámicas sociales diversas. Algunas de carácter macro o global, responsables de procesos de interdependencia creciente entre sociedades. Otras, de tipo micro o incluso interpersonal, afectan a nuestras actividades cotidianas o a nuestro universo relacional, y se dejan sentir en el día a día de cualquier ciudadano. Es más, es tal la rapidez con la que el sector de la información va evolucionando, penetrando, si bien desigualmente, que sus repercusiones parecen hacerse menos impactantes y extraordinarias. El ciudadano medio, acostumbrado a la constancia del cambio, parece percibir la mutación como consustancial a su contexto social.

Tiempo atrás, también la televisión se rodeó de ese halo de modernidad que embarga hoy algunos de los productos tecnológicos más incipientes. Pero además, la llegada de la pequeña pantalla, en el caso español, estuvo asociada a otros significados mucho más trascendentales, que cobraban fuerza en un entorno menos familiarizado con el cambio. La primera televisión aparece vinculada, en el imaginario colectivo español, con el arranque de este proceso de modernización. La caja mágica ejemplificaba el progreso, y con él la apertura a la sociedad de consumo, a la educación, y quizás a la liberalización política. Sin embargo, en la medida en que el televisor se ha situado en otros contextos sociales, el sentido que asociado también se ha visto alterado. El profundo proceso de transformación que la sociedad española ha venido experimentado desde los años sesenta hasta nuestros días explica que este medio se haya revestido de significados mucho más pragmáticos y menos simbólicos. Progresivamente fue perdiendo las connotaciones de "palanca de modernización”, para consolidarse, básicamente, como medio de entretenimiento y fuente de distracción y consumo. Igualmente, su viejo carácter de "dispositivo comunitario en las clases populares" fue difuminándose en la medida en que se instaló en el espacio intrahogar (Callejo, 1995:80-91). La exposición a este medio, menos grupal que en sus primeros momentos, se convirtió en fuente importante del ocio individual, pero sobre todo, del familiar. Los años setenta y ochenta sirvieron para reforzar la vocación de

\footnotetext{
El presente trabajo se enmarca en los siguientes proyectos de investigación:

Proyecto de investigación financiado por la convocatoria "Creación y consolidación de grupos de investigación” BSCH-Universidad Complutense de Madrid, Gr 58/08, "Historia y estructura de la comunicación y el entretenimiento” (ref. 940439).

HAR2008-06076/ARTE, sobre cultura, consumo y contenidos audiovisuales (cine, radio y televisión) en el caso español, financiado por el Ministerio de Ciencia e Innovación, España.
} 
producto de consumo con la que, de hecho, nació la ventana mágica en España. De este modo, a lo largo de este período su visionado se institucionalizó como una de las actividades diarias y casi obligadas de los españoles, quienes depositaron en él, básicamente, expectativas de esparcimiento y evasión.

El proceso a través del que la primera televisión se fue modernizando y por ende, diversificando, primero en forma de varios canales estatales (centrales y autonómicos), después integrando la iniciativa televisiva privada, se inserta en una dinámica de cambio social más amplia y general. La televisión, como se tendrá la oportunidad de detallar, ha desarrollado aquí un doble rol: por un lado, en calidad de medio que nutre e incentiva el cambio. En este sentido, merece destacarse su papel en la consolidación de una sociedad de consumo postindustrial; por otro, como pantalla en la que se reflejan transformaciones sociales, apuntando y señalando tendencias propias de la sociedad española.

Sobre estas coordenadas, el presente trabajo pretende poner de manifiesto la capacidad del medio televisivo, no sólo para activar dinámicas de cambio social, sino sobre todo para hacerse eco de las mismas a través de los relatos televisados. Más concretamente, nos interesan las conexiones entre la pequeña pantalla y la mutante institución familiar. De este modo, nos ocuparemos, fundamentalmente, del rol televisivo en el escenario de las nuevas formas familiares, así como de la representación que este medio propone en torno al universo familiar. A partir de ahí, nos interesa discernir, tanto las utilidades de la pequeña pantalla para esta institución, como las imágenes familiares que el medio devuelve a sus públicos.

En este sentido, este trabajo arranca con una digresión macro sobre televisión y sociedad en la que señalaremos, muy sucintamente, las conexiones entre algunas de las dimensiones de nuestro proceso de modernización y el desarrollo del medio televisivo, haciendo un especial hincapié en la capacidad de cambio social asociada al medio. Seguidamente, este análisis de funciones y utilidades televisivas se concretará en el terreno familiar. Para ello se desgranarán algunos de los mecanismos de relación entre el medio y sus públicos, indispensables para explicar las fórmulas de interacción entre la televisión y el entorno familiar, espacio de recepción televisiva por excelencia.

Finalmente, la última parte del trabajo se centra en dibujar la representación televisiva forjada en torno a la institución familiar, así como la relación comunicativa entre narración y familia. Para ello, este texto parte de la selección de algunos de los formatos contemporáneos de producción nacional, que incluyen entre sus contenidos la temática familiar, y que han venido dando forma a las parrillas televisivas de las generalistas nacionales durante los últimos noventa y primeros años del siglo XXI. Efectivamente, nuestro análisis no pretende realizar una revisión exhaustiva de la programación de presente, de ahí que la parrilla televisiva no se agote en los relatos analizados. Nuestra estrategia metodológica opta, por la selección calculada 
de algunos discursos significativos que apuntan con claridad modalidades de representación hegemónicas en la pequeña pantalla, que entendemos ejemplifican muy bien la función socializadora del medio.

A partir de ahí, se ha recurrido a un muestreo de corte intencional, a través del que se ha realizado una selección estratégica de casos (Valles, 1997). Procedimiento éste que ha servido para recoger contenidos representativos, tanto en términos de popularidad y de seguimiento de audiencias, como en términos de riqueza textual, de despliegue de significantes y significados en torno a la institución familiar. Como resultado de nuestras decisiones muestrales, tanto la ficción, como la información "espectacularizada" ocupan un lugar en la muestra escogida. Las teleseries nacionales, en diversas de sus acepciones genéricas (drama, comedia, telenovela), dan forma al elenco de discursos de ficción seleccionados. En el plano informativo, los programas magazine de tonalidad rosa serán los utilizados para identificar la representación familiar articulada. La aplicación de la técnica de análisis de contenido, en su formulación cualitativa, permitirá entonces identificar claves discursivas generales de los formatos estudiados, así como del medio en cuestión. Categorías de análisis como los personajes, las temáticas, las tramas y subtramas, los escenarios, así como características formales, o funciones y utilidades atribuidas a la institución familiar nos permitirán profundizar en la representación televisiva de este objeto, así como en el sentido ideológico de estos textos.

\section{Consumidor, telespectador y tiempo libre: mercado y ocio}

El modelo de televisión multiplicada o competitiva, que se inicia en los años ochenta con la irrupción de las autonómicas, se completa en los primeros noventa con la llegada de las privadas. Efectivamente, la primera organización monopolística del sector, durante mucho tiempo condensada en dos cadenas de titularidad pública, entraba en contradicción con la exaltación de valores como la diversificación, la competitividad, o la libertad de selección y compra, esenciales en todo sistema sustentado en el consumo. De ahí la importancia de extrapolar la capacidad de elección al sector televisivo, que progresivamente se habría de ir configurando como mercado, integrado ya por una pluralidad de actores, públicos y privados, que ofertan parrillas, contenidos, o productos televisivos.

La Ley de la Televisión Privada, aprobada en mayo de 1988 supuso el primer punto de llegada de un largo recorrido a través del que, progresivamente, se fue ampliando la oferta televisiva. El reconocimiento legal a la iniciativa privada en este ámbito se materializó, en un primer momento, en la adjudicación de tres nuevos canales a sendas sociedades de titularidad privada (Antena 3 de televisión S.A., Gestevisión- Telecinco, y Sociedad Española de Televisión Canal Plus) que comenzaron a emitir sus programas con regularidad en los meses de enero, marzo y septiembre de 1990 respectivamente. 
La propia televisión, en tanto que productora y distribuidora de productos, se situaba por primera vez en un escenario competitivo. De ahí que los usos de programación, producción, financiación, captación de audiencias... se vieran necesariamente alterados por la rivalidad entre canales. Frente a la diversidad de la demanda, la oferta, obligadamente, requería de la diferenciación y la flexibilidad que el propio sistema productivo utiliza para la generación de muchos otros artículos. Las generalistas, de este modo, intentaron adecuarse a las preferencias de sus "grandes consumidores", caracterizados por distintos perfiles en diferentes momentos del día. La segmentación temática y genérica de la programación por franjas horarias es la consecuencia directa de este objetivo. No obstante, las televisiones mayoritarias han buscado mecanismos de distinción, imprimiendo a sus formatos su propia imagen de marca. El caso extremo de esta tendencia toma forma a través de los canales codificados y temáticos, alternativa de una minoría que, a principios del XXI, se “distingue” por el consumo de contenidos televisivos más caros y más exclusivos.

Pero el papel de la televisión en el escenario de la sociedad de consumo no se agota en su labor de productora y distribuidora. Resta decir, que en este complejo engranaje en el que los consumidores perciben el acto de comprar como una necesidad, los medios de comunicación de masas han ejercido un importante papel de mostración de bienes varios, publicitándolos, creando la necesidad y el deseo de poseerlos. De este modo, la pequeña pantalla ha ejercido el papel de ventana a través de la que los espectadores se han podido asomar al escaparate del consumo.

Durante la década de los sesenta, los ciudadanos españoles se sirvieron de ella para iniciarse en la lógica del gasto, para guiar sus preferencias y sus comportamientos de compra, o para visionar lo deseable. En la actualidad la televisión ha seguido ejerciendo esa función, si bien en el contexto de la oferta opulenta y diversificada. De ahí que los mensajes publicitarios hayan adquirido también un carácter más concreto, orientándose a grupos con perfiles sociodemográficos muy nítidos. La televisión ha seguido mostrando a los compradores cuáles han de ser sus deseos, variados y articulados conforme a las características del grupo en el que se insertan. Si bien la consolidación del negocio publicitario es una buena muestra de cómo este tipo de mensajes repercuten en nuestras pautas de compra, el grueso de los consumidores no lo percibe así, o quizás no está dispuesto a reconocerlo. De hecho, algunos trabajos por encuesta señalan como la mayoría de los entrevistados afirma que la publicidad no le afecta a la hora de realizar sus compras. (Cires, 1995: 189).

Si bien la ventana mágica ha hecho las veces de acicate de una sociedad de consumo crecientemente consolidada, también a través de su pantalla se vienen percibiendo otras dimensiones del cambio social responsables de la transformación estructural de la sociedad española. El proceso de urbanización, des- 
agrarización y terciarización, la consolidación de las clases medias, el peso creciente de las ocupaciones no manuales, la transformación de los modelos familiares, la definición de las reglas del juego democrático, la ampliación del tiempo libre... son sólo algunas de las coordenadas de la modernidad, que a su vez han ido modelando y reflejando en el medio televisivo.

Obviamente, el universo de cambios estructurales que van tomando forma desde la llegada de la televisión hasta prácticamente nuestros días tiene su traducción en el plano axiológico y valorativo. De hecho, los estudios de valores europeos han puesto de manifiesto que, ya a lo de las últimas décadas, los españoles perciben que su calidad de vida ha mejorado, y su "satisfacción general" es mayor (Orizo, 1992: 225, CIS, 2000). Por supuesto, en el ranking de prioridades valorativas, el trabajo, sigue manteniendo una importancia de primer orden en nuestro universo de objetivos pero, no obstante, tiene un papel más periférico que antaño, y, de acuerdo con las propias necesidades de una sociedad de consumo consolidada, su percepción es más materialista e instrumental. En este sentido, valores como la salud y la forma física, el estilo de vida, o el tiempo libre se consolidan como fuente intensa de satisfacción personal (CIS, 2004, 2002).

Así, las necesidades de autorrealización tienden a orientarse hacia otros entornos más emotivos y relacionales (Orizo, 1991), vinculados muy especialmente con el tiempo y espacio de ocio, o incluso con el componente hedonista del consumo. En este sentido, es interesante reseñar el prudente ascenso de los valores postmaterialistas, especialmente visibles en el caso de los grupos de edad juvenil (Díez Nicolás, 1991; Orizo, 1991, Torcal, 1989). Los valores vinculados con la expresividad, la autorrealización, la sociabilidad, el desarrollo intelectual, e incluso las preocupaciones estéticas y hedonistas, han adquirido cierta importancia para unas generaciones que no han conocido la inseguridad material y personal propia de las fuertes crisis económicas o los períodos bélicos (Inglehart, 1991). Es el ascenso de este tipo de principios una de las variables explicativas de la participación social en instituciones cívicas, de la preocupación creciente por el medio ambiente o por las diferencias socioeconómicas generadas por la globalización, de la defensa de políticas de coeducación y de igualación entre géneros. Pero al mismo tiempo, el peso de este conjunto axiológico también se deja notar en la importancia de los espacios personales de autorrealización, muy vinculados con el tiempo de ocio, en ocasiones tiempo televisivo.

\section{Televisión y familia. Funciones familiares del medio televisivo}

En el caso español, y desde sus orígenes mismos, el objetivo de la pequeña pantalla pasa por el entretenimiento y la distensión, por la creación de mensajes atractivos y espectaculares que permitan la evasión y el divertimento, tendencia definitoria de lo que se viene denominando televisión comercial (cfr. Rueda y Chi- 
charro, 2006). Siendo así, los contenidos pueden ser recibidos por el espectador y, simultáneamente, reinterpretados y reutilizados para otros usos no siempre previstos por el medio. De ahí que el mensaje pueda servir para presentar y reforzar normas, creencias o actitudes, para proveer una explicación de la realidad presente o pasada, o para crear una imagen autocomplaciente y reconfortante de la realidad. Es decir, su visionado, insertado normalmente dentro de las prácticas de ocio y tiempo libre, está asociado a la realización de funciones psicológicas y microsociológicas para quienes lo consumen.

En este sentido los análisis funcionalistas han señalado cómo el mensaje televisivo puede ejercer las veces de fuente de compañía, dispositivo socializador, o sencillamente, ventana a través de la que asomarse a realidades lejanas geográfica o cronológicamente (Callejo, 1995). Desde esta perspectiva, claramente coherente con el enfoque propio de "los usos y gratificaciones", el receptor tiene la capacidad para "utilizar" el medio en virtud de sus intereses personales, que necesariamente estarán influenciados por sus características sociodemográficas. Detrás de los distintos papeles que realiza la pequeña pantalla estaría la satisfacción de necesidades o motivaciones de sus públicos, hasta tal punto de que un mismo producto televisivo puede ser procesado de diferente manera, mostrando usos varios, adaptados a individuos con necesidades distintas (Katz y otros, 1973).

Este proceso de "utilización televisiva", que atribuye a los espectadores poder para reconvertir los mensajes, implicaría una suerte de lectura interesada. Desde esta perspectiva, el texto televisivo es un discurso abierto, al que se pueden atribuir sentidos varios, dependiendo tanto de elementos contextuales como de la interpretación particular o grupal que los sujetos realicen. Efectivamente, el medio observa ciertas reglas de codificación, con el fin de garantizar cierto ajuste entre el mensaje producido y el recibido (tal es el caso, por ejemplo, de las convenciones de género), y tiende a reproducir códigos dominantes, hegemónicos o preferenciales que pretenden aglutinar a los públicos en torno a consensos valorativos. No obstante, y a pesar de la capacidad de la pequeña pantalla para reproducir ideología, los espectadores tendrían la posibilidad de adoptar varias posiciones frente al mensaje: pueden asumir el punto de vista del emisor (posición hegemónica), pueden crear versiones alternativas, que además refuerzan su identidad diferencial (lectura de oposición), o bien, sencillamente, pueden reconocer las intenciones comunicativas de los emisores aunque no las compartan (posición negociada) (Hall, 1974, Casseti y Di Chio, 1999: 300).

Este proceso es inseparable del referente espacial y simbólico en el que suele tener lugar la recepción televisiva: el entorno doméstico y familiar. De ahí que, en muchas ocasiones, los usos concedidos al televisor no sean tanto individuales como familiares, o cuando menos, se ven mediados por esa recepción frecuentemente colectiva. Por lo tanto, es en el seno de la familia dónde, muy habitualmente, se procesan y 
reinterpretan los contenidos, dónde se da sentido y utilidad a la información, dónde se asume una posición frente a la representación televisiva.

No en vano, la pequeña pantalla, en sus emisiones más populares, se dirige a públicos familiares. Así, la propia organización de la parrilla de las generalistas es un ejemplo nítido de las dependencias familiares que el medio ha establecido. El horario estelar (prime time, 21 hasta casi las 0 horas) que coincide, durante los días laborables, con el momento de descanso e interacción doméstica durante y después de la cena, se ve dominado por formatos pensados para todos. Programas ideados para el grueso de la audiencia, y entre los que domina la ficción dramática, categoría en la que podríamos incluir subgéneros que van desde el telefilme hasta los seriales fruto de adaptaciones literarias, pasando por el teatro televisado.

Entre los contenidos ubicados en la franja más familiar predominan las películas y sobre todo las teleseries nacionales. El término serie hace referencia a un producto televisivo, que se emite en formato episódico o continuado, y que al mismo tiempo obedece a un modo de producción típicamente industrial. La teleserie dramática no es más que un telefilme emitido en forma de capítulos, cada uno de los cuales tiene cierta entidad autónoma, si bien todos ellos aparecen unificados por los personajes, escenarios e incluso por la existencia de una trama general que vincula el conjunto de las entregas.

Buena parte de estos relatos tienen como espacio y como núcleo de la acción la propia interacción familiar (Ana y los siete-TVE1, 2002-2005-, Cuéntame cómo pasó -TVE1, 2001-2008-, Los Serrano -Telecinco, 20032008-, Aquí no hay quien viva-Antena 3, 2003-2006-, Siete vidas, -Telecinco, 1999-2006-...), o bien se sitúan en el espacio laboral, a modo de "segunda morada", (Hospital central, -Telecinco, 2000-, El comisario, Telecinco, 1998-, Periodistas -Telecinco, 1998-2002-, Los hombres de Paco,-Antena 3, 2005-...). Éste último se confunde habitualmente con el ámbito privado, en tanto que en él se traban relaciones significativas y cercanas. En estos casos, la presencia de la familia es más periférica y su lugar en el relato es el resultado de su conexión, entre otros, con el amor romántico o con el valor de la maternidad y la paternidad. Entre tanto, las coordenadas narrativas suelen organizarse en torno a una galería limitada de personajes, fácilmente identificables para el espectador, sí bien lo suficientemente variada como para permitir que la mayoría de los miembros de la unidad familiar, y por extensión, de la audiencia, encuentren un referente de identificación y de proyección.

Los personajes sí tienen un marcado carácter estereotipado, lo que permite, entre otras cosas, simplificar el relato, agudizando la capacidad de previsión. No en vano, se trata de narraciones fácilmente inteligibles, en tanto que pensadas para la evasión de "todos". Habitualmente las temáticas se concentran en los encuentros y desencuentros personales (diferencias entre roles y percepciones según el género, conflictos de 
autoridad en la familia o en el trabajo, enamoramientos, desenamoramientos, engaños amorosos, disensiones entre amigos, incomprensiones entre padres e hijos, o entre jefes y subordinados...). Entroncan directamente con vivencias que el común de los espectadores ha experimentado. De este modo, se afianza la seguridad del espectador sobre el conocimiento del código y la semántica televisiva, y se acrecienta, especialmente en el caso de los grupos más indefensos frente al mensaje televisivo, su sentimiento de control y familiaridad (Callejo, 1995). La temática de lo relacional y lo emotivo permite que los estratos menos instruidos perciban la trama en términos verosímiles y contrastables con la experiencia propia.

En este sentido se ha señalado como la televisión puede llegar a realizar funciones "familiares", a veces, aparentemente contradictorias. Así, es capaz de actuar sobre las identidades de género en el terreno hogareño, introduciendo el mundo público, históricamente varonil, en un entorno como el doméstico, teñido de feminidad (Meyrowitz, 1985); al mismo tiempo, puede llegar a transmitir un dibujo de la domesticidad que favorece la asunción de un rol femenino identificado con el espacio del hogar (Haralovich, 1988); o puede servir para generar emociones, sustituyendo así otros actores que tradicionalmente ejercían este papel (Rogge y Jensen, 1988).

Pero sobre todo, puede establecer un dibujo de los roles y características de la institución familiar (Greenberg, 1980), señalando actitudes, normas, valores, creencias o comportamientos convenientes. En este sentido, algunos trabajos claramente vinculados con el funcionalismo, señalan cómo puede hacer las veces de patrón, de referencia o modelo de aprendizaje: el espectador identifica en la pequeña pantalla una situación que le es familiar, y ante la que puede tener que enfrentarse, y, al mismo tiempo, percibe el diagnóstico y la resolución televisiva como la vía correcta, la que se debe adoptar, para resolver el conflicto de manera más funcional (Casata y Skill, 1983). Por otro lado, el habitual "final feliz" es otro de los elementos que añade convicción a la resolución televisiva. Es decir, la pequeña pantalla nos anticipa las contrapartidas y las gratificaciones de posibles decisiones. No en vano es una historia de ficción, que "podría ser real", y por ello más valorada.

Si bien la ficción televisiva realiza una interpretación de determinadas situaciones personales, del mismo modo, plantea su particular lectura de fenómenos o eventos de índole más general o social. El comportamiento delincuente, el maltrato a las mujeres, el divorcio, la drogadicción juvenil, la inmigración, la pobreza, la soledad y el abandono, las enfermedades de transmisión sexual, las psicopatologías... temáticas que dominan en los formatos informativos, tienen su cabida en determinadas series de corte dramático (Periodistas, El comisario, Hospital Central, Policías -Antena 3, 2000-2003-, Compañeros, -Antena 3, 19982002- ) reflejando en su discurso algunas de las preocupaciones sociales más visibles, si bien a través de un 
enfoque sentimental, emocional. Pero además, el relato suele proveer al espectador de una suerte de interpretación del fenómeno en cuestión, habitualmente explicado en clave familiar. Una infancia difícil, la influencia de un entorno familiar desestructurado, la ausencia de las figuras paternas... son algunas de las variables más recurrentes a la hora de justificar los comportamientos ajenos a la norma de aquellos personajes que dan forma humana a las obsesiones sociales más recurrentes. Casi siempre, el conflicto se resolverá de acuerdo con las expectativas del público, y garantizando la conservación del estatus quo.

Finalmente, y continuando con la mencionada función socializadora, el relato de ficción, a través de su discurso, legitima y visibiliza nuevas formas familiares. Es más, tal y como señalaremos a continuación, éstas, en tanto que televisadas, tienden a convencionalizarse y a presentarse como emblemas propios de la modernidad.

\section{Las mutaciones familiares, televisadas}

Dentro de las grandes transformaciones macro de las que se hace eco la pequeña pantalla, mención especial merece su representación del cambiante universo familiar. La preocupante caída de la tasa de fecundidad, la reducción del tamaño familiar, la pérdida de popularidad de la institución matrimonial, el crecimiento de las parejas de hecho, el incremento de la tasa de separaciones y divorcios, el aumento de las familias monoparentales, monomarentales y reconstruidas son sólo algunas de las tendencias que se vienen atisbando en este mutante escenario. Del mismo modo, la lógica de la interacción y del reparto de papeles en el seno de la familia nuclear también se ha visto sustancialmente alterada. La creciente igualación de los roles femenino y masculino, la reducción de autoridad paterna, así como el valor del diálogo, del consenso y de las actitudes democráticas en el espacio doméstico han vaciado conceptos como el de "conflicto generacional", tan frecuentes a la hora de calificar las relaciones padres-hijos en otros momentos (Alberdi, 1999, Martín Serrano, 1991)

En el relato televisivo de ficción los nuevos modelos familiares enunciados tienen tanta o más fuerza que la institución familiar clásica. De este modo, estas alternativas parecen añadir una mezcla de realismo, pero también de vanguardia, novedad, e incluso exotismo a la trama. En cualquier caso su presencia da cuenta de que se trata de fórmulas cada vez más convencionales y aceptadas, proceso al que contribuye una narración que dibuja esta opción minoritaria en tonalidades muy blancas. Su creciente grado de visibilidad televisiva pone de manifiesto su legitimidad social en aumento.

En este sentido, especialmente ilustrativa es la aportación realizada por las variantes cómicas de las teleseries, situadas en los entornos de la "comedia de situación". Se trata de formatos que optan por un 
tratamiento humorístico y crítico, utilizando escenarios recurrentes, y articulando sus tramas en torno a relaciones y conflictos entre un número reducido de personajes (Barroso, 1996). De nuevo el espacio familiar o, por extensión, el vecinal, planteado éste como una suma de hogares, es el que conecta todo un conjunto de subtramas articuladas a través de personajes más o menos estereotipados. La narración, con claras dosis de teatralidad, se presenta como un intento de acercar al espectador a una historia sobre "familias" en clave de parodia. La estrategia del realismo extremo y absurdo ayuda a construir situaciones cómicas, teñidas de humor negro. De este modo, los personajes, rompiendo algunas de las reglas sociales más básicas, expresan sin tapujos y con total contundencia sus miedos, sus rencores, sus emociones, sus deseos, que exhibidos con sinceridad descarnada y dramática, generan situaciones transgresoras, divertidas e impactantes.

En este sentido, el recurso a fórmulas familiares o cuasi familiares novedosas, permite articular relatos menos previsibles y más originales, con mayores matices de extraordinariedad, y que pueden generar situaciones especialmente transgresoras, fomentando la emoción. Así por ejemplo, la familia reconstituida es el escenario en el que se puede reflexionar sobre la confusión de identidades y la dificultad de extrapolar los roles clásicos a un entorno familiar en el que la vinculación de sus miembros no es necesariamente cosanguinea (Los Serrano). Otros modos de hacer familia, en su versión más simple y reduccionista, también se convierten en el marco adecuado para trabar relatos sorprendentes. Las hermanas solteronas, el divorciado o divorciada, la joven soltera, la viuda que comparte piso, el matrimonio que convive con la hermana... (Aquí no hay quien viva, Siete vidas) son personajes, algunos de ellos ya clásicos en el discurso cinematográfico y televisivo, asentados en el imaginario colectivo y, en consecuencia, reconocibles para el público. Finalmente, estos relatos parecen estar contribuyendo a estereotipar fórmulas familiares que hasta la fecha no tenían una formulación convencional en el mensaje televisivo (tal es el caso de la familia extensa o el hogar monoparental -Aída, Telecinco, 2005-2009- la pareja homosexual -Aquí no hay quién viva-).

La reflexión televisiva en torno a la familia ha adquirido, en algunos formatos de ficción específicos, un tono mucho más retrospectivo y evocador. Y es que la visualización de la institución a través de la perspectiva del tiempo histórico ha demostrado ser una estrategia que permite al espectador conectar con distintos puntos de su propia biografía personal. En este sentido, el ejemplo más representativo es el de Cuéntame cómo pasó que revisa los últimos años del franquismo desde los avatares cotidianos de una familia media. Mediante un discurso nostálgico, el espectador tiene la posibilidad, o bien de situarse en un pasado reciente, almacenado en la memoria, o bien, en el caso de los más jóvenes, de visualizar un período conocido a través de los libros de texto o de las referencias de sus mayores. El vestuario de la época, las actividades de 
tiempo libre, los objetos de consumo, las citas históricas, e incluso las referencias intertextuales, recogiendo programas televisivos emblemáticos, permiten al espectador trasladarse a otro tiempo. En cualquier caso, es la utilización de la familia como núcleo narrativo de la trama lo que facilita el acercamiento al relato.

La narración de Cuéntame cómo pasó se articula como una suerte de epopeya que exalta los avatares de una sociedad que cambia aceleradamente y cuya mutación se deja notar, entre otras, en el terreno familiar. La madre soltera que rehace su vida, la francesa divorciada, el hombre separado que se compromete con la joven sobrina de su hermano, el hijo soltero que se independiza, la abuela jubilada que se ennovia, o la hija que se casa con un sacerdote en vías de secularización son algunas de las situaciones familiares que dan cuenta de que la institución se "moderniza", o al menos esa es la tesis de la teleserie. No obstante, estos personajes que representan la "vanguardia familiar" conviven con otros mucho más convencionales que señalan los elementos de continuidad. La familia nuclear protagonista, dibujada como institución que se adapta y flexibiliza en función de las novedades, es el paradigma de la pervivencia, y hace las veces de factor de continuidad y estabilidad.

Detrás del mencionado intento de mitificar la sociedad española subyace, así mismo, una suerte de discurso de exaltación familiar a través del que el relato devuelve una mirada halagadora a su público. En última instancia, la teleserie no deja de presentarse como una odisea familiar, en la que esta institución se enfrenta a constantes dificultades que logra superar utilizando recursos que se presentan como parte de su esencia. La comprensión, la empatía, la confianza interpersonal, la seguridad afectiva, la tolerancia, la solidaridad, la comunicación... se esbozan a modo de claves explicativas de la solidez familiar y de su capacidad de permanencia. Los héroes cotidianos, básicamente encarnados en los progenitores de la familia nuclear protagonista, superan victoriosos sus gestas diarias, enunciado extensible, como diría el propio narrador del serial, a cualquier familia media de la época.

La utilización de la familia como pilar narrativo central responde entonces a variadas utilidades. En primer lugar, hace las veces de recurso para la elaboración de un discurso catártico. Efectivamente, a través de su visionado el espectador tiene la oportunidad de acercarse como observador a los conflictos cotidianos. Esa toma de distancia le permite vislumbrarlos de una manera amable y desdramatizada. La parodia de la cotidianeidad facilita una visualización de algunas claves del día a día, desde las experiencias de los personajes con los que se conecta. A partir de ahí, los conflictos dibujados en la pequeña pantalla son de utilidad para desmitificar y normalizar las tensiones familiares. Si la televisión acompaña, y referencia puntos y temáticas de conversación (Winick, 1988, Palmgreem, 1984), también puede hacer las veces de mecanismo terapéutico a través del que los propios conflictos se traducen en entretenimiento (cfr. Lacalle, 2000). 
En segundo lugar, es en este tipo de formatos, los que versan sobre familias y se dirigen a públicos familiares, donde se explicita de manera más clara cuanto de teatral tiene buena parte de la interacción familiar más convencional. El respeto a nuestros mayores, la confianza interpersonal, la preocupación de los padres hacia sus hijos, la sinceridad, o el apoyo mutuo son algunas de las normas familiares conforme a las que somos socializados y que sirven de guía en el ejercicio de estos roles. Sin embargo, la representación televisiva pone de manifiesto el carácter construido y artificial de este engranaje mediante personajes exagerados y extremos, que ejercitan los roles familiares de manera poco convencional y que, aún siendo familia, rompen con el deber ser de la institución. El espectador puede visionar otras maneras de comportarse en este entorno: la propia del "mal hijo", la del "abuelo transgresor", o del "hermano incorrecto". Del mismo modo, puede percibir los efectos que estos comportamientos a través de los personajes afectados: desde la "madre sobrepasada", hasta el "padre incapaz".

De este modo, estos formatos, bajo el lema manifiesto del entretenimiento, dejan patente su carácter latente de ejercicios de reflexión a través de los que se expresa la rigidez de las reglas familiares y, al mismo tiempo, su constante redefinición. Esta situación se explicita especialmente en la representación que la televisión hace de la familia reconstruida (Los Serrano). El matrimonio que convive con hijos propios, a los que se suma la descendencia de otras relaciones, es la tesitura adecuada para redefinir roles ya obsoletos. De ahí que la legendaria "madrastra”, en su versión actualizada, mantenga con los hijos de su marido una relación amistosa, minimizando el vínculo materno filial. O del mismo modo, la convivencia de "hermanastros", que no comparten lazos de sangre, abre la posibilidad a conexiones hasta la fecha inverosímiles, como es el amor romántico. El objetivo es el de construir conflictos realistas que agudizan la tensión dramática de un relato de ficción, pero cercano y familiar.

\section{Las aristas familiares: el lado oscuro de la cotidianeidad}

Este dibujo optimista y positivo de la familia no es una nota coincidente en el grueso de los formatos. El entorno familiar y sus inmediaciones tienen otras lecturas, caracterizadas por un tono mucho menos triunfalista, y sí más crítico, aunque no exento de interés para los públicos.

Éste es el caso de los comúnmente denominados "programas del corazón”, formatos de información que recurren a la suma e hibridación de géneros dialógicos (entrevista, el debate, el coloquio, la tertulia) para acercarnos a aspectos sentimentales y emocionales y, por ende, familiares de personajes "populares" Programas como Dónde estás corazón (Antena 3, 2003-), Salsa rosa (Telecinco, 2002-2006), Dolce Vita (Telecinco, 2006-2007), La noria, (Telecinco, 2007-), Gente, (TVE 1, 1995-) que, aderezados con claros tin- 
tes de telerrealidad, utilizan estrategias dramáticas e interpretativas con el fin de agregar componentes de espectacularidad, a costa de desvirtuar su aparente función informativa. La utilización de polígrafos, los tintes teatrales y forzados de buena parte de los personajes, los interesados montajes de imágenes, la repetición constante de planos o secuencias impactantes, la práctica de la recreación y la simulación... Todo ello convenientemente adornado con la intervención de periodistas en el plató: el exagerado volumen de su voz, el uso de términos irrespetuosos, su propensión a la discusión y al conflicto, la directividad de sus preguntas, su constante evaluación de los personajes... En última instancia, la utilización de mecanismos propios de la ficción televisiva, pero presentados como garantía de realismo, acercan este tipo de formatos a la lógica del reality show.

En estos casos, personajes que encarnan algunos de los valores sociales en alza (dinero, poder, fama, belleza, lujo...) muestran sus entresijos familiares, tanto más interesantes, en tanto que negativos y dolorosos. La infidelidad, la separación y el divorcio, el desamor, el desengaño personal, el maltrato, la drogadicción, la pobreza, la enfermedad... son las claves narrativas de estos relatos que permiten al público atisbar las aristas biográficas de individuos aparentemente envidiables. Tanto es así que el espectador puede hacer uso de su capacidad para identificarse y sobre todo para proyectar en el relato las propias miserias personales que, obviamente, se minimizan cuando se comparan con las desgracias televisadas. Este dibujo negativo y desgraciado de la institución familiar conecta directamente con los relatos propios de los talk shows matinales y vespertinos, otra de las dimensiones televisivas del "no deber ser de la familia". Efectivamente, en este caso, si bien las tensiones familiares son del mismo calibre, se ejemplifican en individuos anónimos con los que el espectador puede, más fácilmente, establecer relaciones de identificación e incluso utilizar el relato y sus personajes a modo de canal terapéutico y catártico (Lacalle, 2000, Chicharro y Rueda, 2005).

Esta estrategia de dramatización de lo emocional propia de la telerrealidad también tiene presencia en algunos formatos de ficción. Si en el caso de los géneros informativos la centralidad de lo sentimental lleva a mostrar el lado familiar más privado y socialmente reprochable, esa lógica se reproduce en fórmulas como la telenovela o el culebrón. En este caso, personajes que representan el lujo y el poder conviven con otros que simbolizan la dificultad y el deseo de movilidad social, dando lugar a una narración ramificada, en la que los sinsabores familiares tienen una especial relevancia. Caracterizado por su extraordinaria duración, a través de capítulos diarios con finales siempre abiertos, el culebrón tiene en su tono melodramático su principal seña de identidad. Tanto es así que en él los aspectos sentimentales y emocionales adquieren una centralidad que el espectador puede visualizar a través de conflictos variados que se materializan en amores imposibles, ilegales y clandestinos, no correspondidos, agravios y afrentas, infidelidades amorosas, abusos de poder... (Barroso, 1996). 
Este esquema se ejemplifica muy claramente en un conocido culebrón de producción española, ambientado en torno al escenario de la guerra civil y sus entornos. Amar en tiempos revueltos (TVE1, 2005-) articula su trama principal, en torno a las dificultades de varios amores aparentemente imposibles y limitados por las circunstancias (Chicharro, 2009, Chicharro y Rueda, 2008). De nuevo en este caso, el relato nos permite recuperar la trayectoria mutante de la institución familiar y matrimonial, desde una perspectiva diacrónica. Desde el matrimonio convencional, pasando por el nulo (aquellos que tuvieron lugar durante la II República y que posteriormente fueron declarados ilegales), hasta llegar a la unión ilegal o al concubinato. De este modo, la telenovela, más que realizar una representación de las formas matrimoniales y familiares de la época, nos explica y justifica esta realidad en el presente señalando sus fisuras en el pasado. En realidad, se acerca al universo familiar desde presupuestos contemporáneos, más que desde valores de la época, pero en cualquier caso provee al telespectador de explicaciones de utilidad para entender la institución en la actualidad y para reforzar su valor.

\section{Conclusiones}

En el ejercicio de su función socializadora, el medio televisivo gusta de proponer relatos a través de los que establecer relaciones significativas con sus públicos. En este sentido, la referencia a la institución familiar entronca con nuestra realidad más cotidiana y privada, más emotiva y primaria, lo que permite que se establezcan relaciones de cercanía entre el público y el mensaje televisivo.

Pero más allá de la temática familiar como recurso narrativo, su inevitable presencia en el discurso televisivo se explica desde la relevancia social que la institución tiene. No en vano, es especialmente valorada, y en esta evaluación compartida descansa uno de los focos de consenso e integración valorativa de la sociedad española (Requena y Benedicto, 1988). Más allá de la importancia atribuida, la realidad empírica constata el papel que ha desarrollado a la hora de superar situaciones de dificultad social (desempleo, cuidado de los hijos, pérdida de poder adquisitivo frente a la jubilación...), que en otros países vienen siendo subsanadas por un fuerte estado del bienestar. De este modo, se ha señalado como la debilidad del estado puede contribuir a la conservación de la familia en su versión más clásica (Popenoe, 1988, 1991).

En tanto que eje de vertebración social, los textos sobre familias son universales e inteligibles para todos, y además de ofrecer una representación de esta realidad en su dimensión macro, nos proveen de pautas de interacción micro. Tanto es así que, independientemente del formato, los dibujos familiares juegan a señalar al espectador las reglas del juego dentro de ese espacio y, obviamente, a reforzar la importancia de su 
papel, tanto en su versión más clásica (la familia nuclear), como en sus materializaciones más recientes. Tanto en sus lecturas más idílicas, como en las más obscenas, la familia tiende a ser reforzada.

Efectivamente, el presente trabajo centra su atención, exclusivamente, en algunos relatos de ficción e información significativos en las parrillas de las TV generalistas españolas. De ahí, que, si bien responde a algunos de los interrogantes sobre la relación entre televisión y familia, también señale algunas líneas de investigación pendientes de continuidad. A partir de aquí, resta saber, por ejemplo, si la mencionada función socializadora ejercida por la televisión es extrapolable a otros discursos informativos más ortodoxos (tal es el caso de los telenoticias), así como a otros formatos híbridos, que aúnan información y ficción, introduciendo recursos telerreales (docushows, infoshows, talk shows...). Del mismo modo, cabe preguntarse si otras vías textuales abiertas por la ficción, tanto nacional como extranjera, mantienen el mencionado discurso reforzador de la familia o, por el contrario, positivizan especialmente otros entornos de sociabilidad distintos de los parentales.

En cualquier caso, la importancia subjetiva y objetiva de esta institución justifica el interés y la utilidad que la temática despierta. Así, tal y como se ha señalado, en muchos de los relatos televisados la familia hace las veces de actor; el público familiar ejerce de audiencia (Spigel, 1992). O lo que es lo mismo, la institución toma conciencia de sí misma y de su existencia pluriforme y adaptable. A través de las imágenes, a veces negativas, pero sobre todo engrandecedoras que le devuelve la pequeña pantalla se señalan sus mutaciones, pero también sus continuidades, reafirmándose su carácter de universal cultural, así como su función manifiesta más significativa: la de entorno de seguridad para el sujeto.

\section{Referencias bibliográficas}

Abruzzese A.; Miconi, A. (2002): Zapping. Sociología de la experiencia televisiva. Madrid: Cátedra.

Adorno T. W.; Horkheimer, M. (1944): Dialéctica de la ilustración. Madrid: Trotta.

Alberdi, I. (1999): La nueva familia española. Madrid: Taurus.

Callejo J. (1995): La audiencia activa. Madrid: Centro de Investigaciones Sociológicas.

Cassata, M.; Skill, P. (1983): Life on Daytime Televisión: Turning in American Serial Drama. Norwood: Ablex.

Casseti, F.; Di Chio (1999): Análisis de la televisión. Instrumentos, métodos y prácticas de investigación. Barcelona: Paidós.

Beltrán M. (1992): “Terremotos en los cimientos de la estructura social española”. C. Moya et al. (comps.), en: Escritos de teoría sociológica en homenaje a Luis Rodríguez Zúñiga, pp. 135-143. Madrid: Centro de Investigaciones Sociológicas. 
Centro de Investigaciones Sociológicas, (2004): Datos de opinión, no 36, septiembre-diciembre, 2004, www.cis.es

- (2002): Datos de opinión, no 28, enero-abril, 2002, www.cis.es

- (2000): Datos de opinión, no 25, julio-septiembre, 2000, www.cis.es

Chicharro, M (2009): “Información, ficción, telerrealidad y telenovela. Algunas lecturas televisivas sobre la sociedad española y su historia”. Comunicación y Sociedad, no 11, enero-junio2009. México: Universidad de Guadalajara.

Chicharro, M.; Rueda, J.C. (2008): “Ficción y representación histórica: Amar en tiempos revueltos”. Comunicación y Sociedad, no 2, p. 57-84.

- (2005): Imágenes y palabras. Madrid: Centro de Investigaciones Sociológicas.

Cires (1995): La realidad social en España, 1993-94. Madrid: Fundación BBV-BBK y Caja de Madrid.

Díez Nicolás, J. (1991): “Prólogo”. En: INGLEHART, R. El cambio cultural en las sociedades industriales avanzadas. Madrid: Centro de Investigaciones Sociológicas, XI-XIX.

Garmendia, J.A. (1987): “Nuevas tecnologías, empleo y ocupación”. En: J. A. Garmendia, M. Navarro (eds.). Sociología Industrial y de la empresa. 151-174. Madrid: Aguilar.

Greenberg, B. (1980): Life on Television Content Analysis of U.S. TV Drama. Norwood: Ablex,

Hall, S. (1974): “Encoding/Decoding in Television Discourse”. En: S. Hall et al Culture, Media, Language: Working Papers in Cultural Studies. Londres: Hutchinson.

Haralovich, M. B. (1988): "Suburban Family Sitcoms and Consumer Product Design: Addressing the Social Subjectivity of Homemakers in the 1950s". En: Television and its Audience: International Research Perspectives. (P. Drummond, R. Paterson (eds.)). 38-60. Londres: British Film Institute.

Inglehart, R., (1991): El cambio cultural en las sociedades industriales avanzadas. Madrid: Centro de Investigaciones Sociológicas.

Barroso, J. (1996): Realización de los géneros televisivos. Madrid: Síntesis.

Katz E., Blumler G., Y Gurevitch M., (1973): “Uses and Gratifications Research”. Public Opinion Quaterly, 37-4, 509-23.

Spigel, L. (1992): Make Room for TV: Television and the Family Ideal in Post-War America. Chicago: Chicago University Press.

Lacalle Ch. (2001): El espectador televisivo: los programas de entretenimiento. Barcelona: Gedisa.

- (2000): “Mitologías cotidianas y pequeños rituales televisivos: los talk shows”. Análisi, no 24, 79-92.

Martín Serrano, M. (1991): “Tres visiones del mundo para cuatro generaciones de jóvenes”, en: M. Martín Serrano Historia de los cambios de mentalidades entre 1960-1990, pp. 17-54. Madrid: Instituto de la Juventud. 
Meyrowitz, J. (1985): No Sense of Place: The Impact of Electronic Media on Social Behaviour. Nueva York: Oxford University Press.

Morin, E. (1983): L’esprit du temps. París: Librairie générale française.

Orizo, F. A. (1991): Los nuevos valores de los españoles. Madrid: Fundación Santa María-SM.

- (1992): “La sociedad del bienestar", en: A. de Miguel: La sociedad española 1992-93. Madrid: Alianza Editorial.

Palmgreen, P. (1984): “Uses and Gratifications: A Theoretical Perspective”, en: R. N Bostrom (ed.): Communication Yearbook, pp. 20-55. Newbury Park CA: Sage.

Popenoe, D. (1988): Disturbing the Nest: Family Change and Decline in Modern Societies. New York: Aldine,

- (1991): “Family Decline in the Swedish Welfare State”. The Public Interest, no 102, pp. 65-77.

Postman N. (1991): Divertirse hasta morir. Madrid: Ediciones La tempestad.

Requena M.; Benedicto J. (1988): Relaciones interpersonales: actitudes y valores en la España de los ochenta. Madrid: CIS.

Rogge U.; Jensen K. (1988): "Everyday Life and Television in West Germany: an Empathetic-Interpretative Perspective on the Family as a System”, en: J. Llull (ed.): World Families Watch Television, pp. 8-115. Londres: Sage.

Rueda, J.C., Chicharro, M. (2006): La televisión en España, 1956-2006. Madrid: Fragua.

Torcal, M. (1989): "La dimensión materialista/postmaterialista en España: las variables del cambio cultural”. Revista Española de Investigaciones Sociológicas, $\mathrm{n}^{\circ}$ 47, pp. 227-254.

Valles, M. S. (1997): Técnicas cualitativas de investigación social. Madrid: Síntesis.

Winick, C. (1988): “The Functions of TV: Life without the Big Box”, en: S. Oskamp: Television as a Social Issue. S. pp. 217-237. Newbury Park CA: Sage. 